\title{
REMARKS MADE BY MANLEY CALLIN
}

\section{ON THE OCCASION OF THE BOOK-LAUNCHING, SASKAT- CHEWAN NATURAL HISTORY SOCIETY SUMMER MEET, ROUND LAKE JUNE 6, 1980}

They say confession is good for the soul, and I have a few confessions to make.

1. I am not used to speaking and generally avoid it, so you can expect an absolute minimum of quantity and quality.

2. The book shows dates of 1857-1979 - one hundred and twenty-two years. This is not really my age $-\mathrm{I}$ am not a day over 100 .

3. Speaking of time - the completion of this project has taken so long that I began to wonder whether the date was 1857 B.C. or 1857 A.D.

4. I must also confess to four bad habits:
a) I smoke
b) I drink
c) I am a girl-watcher
d) I am a chronic bird-watcher. In fact, my doctor has diagnosed my birdwatching as a "terminal" case!

5. All of these things have taken their toll. Therefore I am suffering from an energy crisis - which, of course, is the "in" thing nowadays. I will not be able to cover the ground today that many of you can.

6. I will be receiving a lot of credit to which I am not entitled. As you can see, many observers have contributed records, but I am thinking especially of the tremendous amount of work that Stuart and Mary Houston did. Stuart compiled the historical records, and acted as prodder and editor. Mary typed the manuscript in 1967 and 1979. They should be receiving hearty and bountiful congratulations.

End of confessions. Now for a bit of miscellaneous information.

1. I have been coming to Round Lake for 46 years - with few exceptions, we have made an annual one-day visit each year since 1933 - it has always been very interesting (see p.33 of Birds of the Qu'Appelle, 1857-1979).

2. Depending on weather and the areas covered, one may expect anywhere from 75 to 100 species in one day at this time of year.

3. There are many special species that are more likely to be found here than in the parklands above. Three stand out as characteristic of the valley - the Veery, Rufous-sided Towhee and Rose-breasted Grosbeak. Nine more northern species, twelve water birds, nine raptors, the Ruffed Grouse and fifteen song birds, are listed on pages 24 and 25 of the book as regular in the valley but rare or absent in the parklands above.

I hope you see and hear many of these special birds in your field trips this weekend.

Thank you. 